\title{
RESEARCH ON ASSESSMENT METHOD FOR RURAL INFORMATIZATION LEVEL BASED ON AHP
}

Du Jing ${ }^{1,3}$, Daoliang $\mathrm{Li}^{2}$, Hongwen $\mathrm{Li}^{1{ }^{1, *}}$, Yanjun Zhang ${ }^{2}$

${ }^{1}$ College of Engineering, China Agricultural University, Beijing, P. R. China 100083;

${ }^{2}$ College of Information and Electrical Engineering, China Agricultural University, Beijing, P. R. China 100083;

${ }^{3}$ China Agricultural University Library, Beijing, P. R.China, 100083

* Corresponding author, Address: P. O. Box 46, College of Engineering, China Agricultural University, 17 Tsinghua East Road, Beijing, 100083, P. R. China, Tel:+86-10-62737631, Fax:+86-10-62737300,Email:Ihwen@cau.edu.cn

Abstract: Based on rural informatization connotation and five essential elements that affect rural informatization assessment, which are development environment, information infrastructure, information resource, information service system and application of information technology in rural areas, This paper designs an indicator system for rural informatization level assessment. Through AHP method, it sets up the hierarchical construction model of rural informatization assessment and weight of each indicator is calculated. Thus the evaluation method for assessment on rural informatization level is proposed in this paper. It combines subjective evaluation with objective appraisal and will help direct rural informatization management departments with jobs and promotes rural informatization development.

Keywords: Rural informatization; Assessment, Analytic Hierarchy Process(AHP); Indicator system

\section{INTRODUCTION}

Agriculture and rural informatization is an important component of the national economy informatization. Rural informatization is the inevitable requirment to realize countryside modernization and an important means of

Please use the following format when citing this chapter:

Jing, D., Li, D., Li, H. and Zhang, Y., 2009, in IFIP International Federation for Information Processing, Volume 295, Computer and Computing Technologies in Agriculture II, Volume 3, eds. D. Li, Z. Chunjiang, (Boston: Springer), pp. 1899-1907. 
resolving the problems facing our agriculture, rural areas and farmers (Zang Chunrong et al., 2004). By strengthening rural broadcast television networks, telecommunication and computer networks and other information infrastructure construction, fully developing and using each kind of information resource, constructing comprehensive information platform and service system, promoting the exchange of information and knowledge sharing, Rural informatization will promote the application of advanced information technology in countryside production and management, public services, government affairs management, life expense and so on each aspect(Tan Guoliang et al., 2007).

Rural informatization assessment is to evaluate the level and effect of rural informatization construction by adopting mathematical statistics, operation research principle and specific indicator system (Liu Shihong et al., 2007).To do that, It should compare the unified standard, compute quantitativly and qualitatively and make contrastive analysis in accordance with certain procedures. By evaluating rural informatization level of our country through quantitative analysis method, the rural informatization conditiongs of different area and rural informatization degree of the same area can be revealed quantitatively (Sheng Qifeng et al., 2005). Evaluating rural informatization level comprehensivly and scientificly, measuring and grasping the information development level of each rural area accurately will help to find problems and shortcomings in the process of rural informatization, thus to direct every area to get information technology work forward and provide basis for formulating long-term rural informatization development planning and information-based strategy (Yi Yaxin et al., 2004).

\section{INDICATOR SYSTEM OF RURAL INFORMATIZATION ASSESSMENT}

Rural informatization assessment is a huge system engineering that synthesizes technological innovation and institutional innovations. Its implementation involves all aspects of rural business and information techonology (Qin Xiangyang et al., 2008). The comprehensive assessment of rural informatization belongs to information system appraise category and involves assessment on many aspects of rural informatization such as exterior development environment, information infrastructure, rural information resource, information organizations and agencies engaged in the countryside information service work and application of information technology in rural areas. 


\subsection{Selection of indicator}

The core content of rural informatization assessment includes five mutually and closely contacted planes: development environment, information infrastructure, information resource, information service system and application of information technology in rural areas. Rural informatization assessment bases on the construction of scientific and rational evaluation indicator system. In order to objectively evaluate the level, indicators that affect rural informatization level should be selected according to results of expert consultation and questionnaire survey. Factor choice should obey the following principles(Liu Shihong et al., 2007; Lu Lina et al., 2007):

1) Comprehension: The factor must reflect each side of the appraised object and study its connotation and extension deeply in the process of construction, making every effort to fullly and actually manifest it.

2) Operability: Weight of each indicator shoule be determined based on the actual development of rural informatization. The evaluation method stresses on availability of indicator data.

3) Guidance: Prospective and tendency factors should be introduced to guide the direction of rural informatization development.

4) Connection: The indicator system should link up with national and regional informatization assessment index system and reflect the development characteristic of rural informatization downward.

5) Comparability: International and domestic general targets should be introduced in. Each target should be fairly comparable corresponding to every appraised object.

\subsection{Construction of indicator system}

According to the concept of rural informatization and above principles, This paper chooses twenty indicators from the above five planes of rural informatization. Its schematic diagram is shown in Fig.1. 


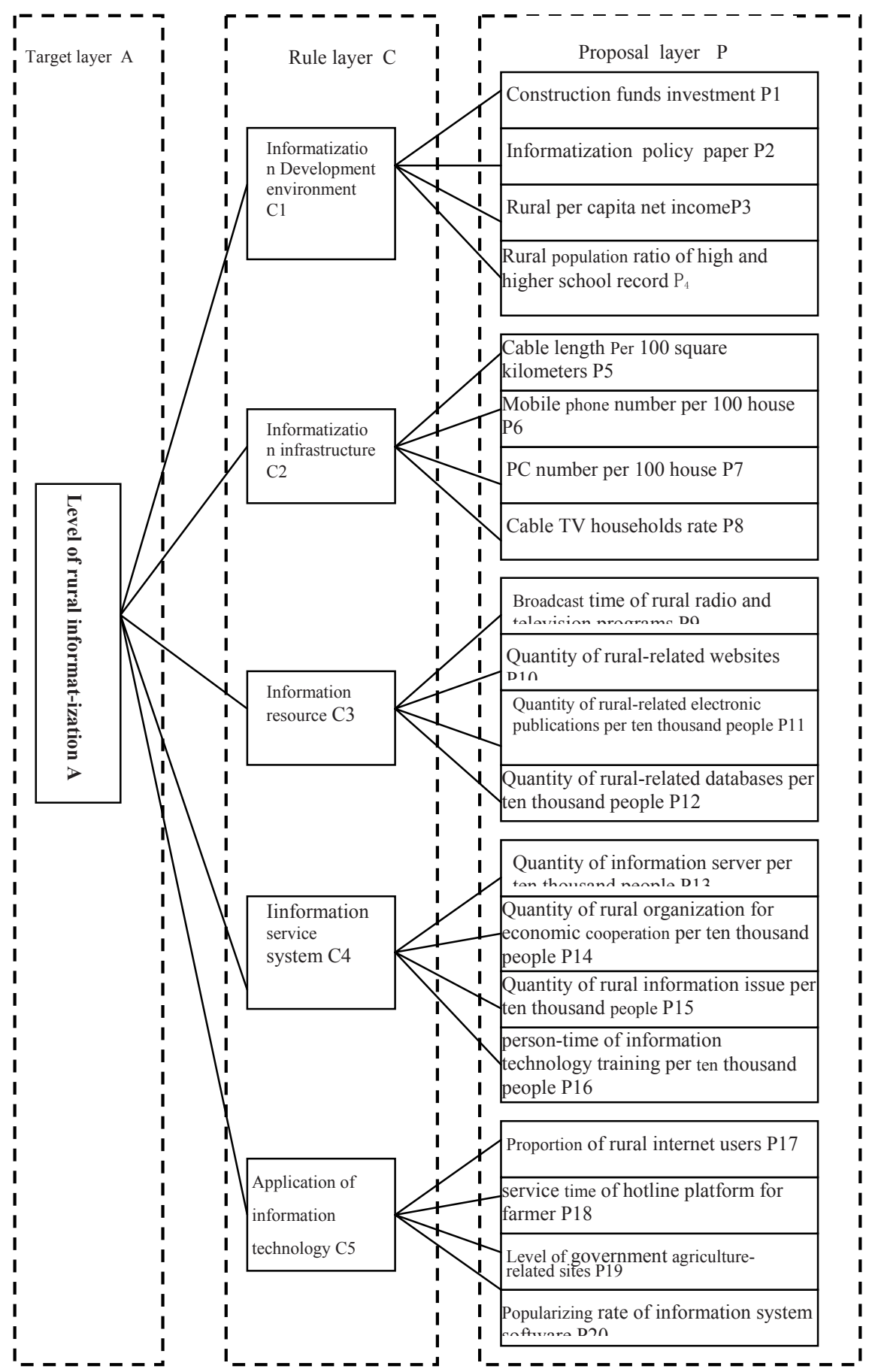

Fig. 1: Hierarchical construction of rural informatization assessment 


\section{MODEL OF RURAL INFORMATIZATION ASSESSMENT}

\subsection{Form assessment indicator set}

Based on the indicator system above, the assessment factor set $X$ could be formed and expressed as $X=\left\{X_{1}, X_{2}, X_{3}, X_{4}, X_{5}\right\}$, And $X_{i}=\left\{X_{i 1}, X_{i 2}, \cdots, X_{i j}\right\}$, $(i=1,2,3,4,5 ; j=1,2,3,4)$.

\subsection{Establish stepped hierarchical construction}

The graded hierarchical construction model of rural informatization assessment includes three layers, they are: the level of rural informatization development, the main content of rural informatization and the rural informatization assessment factors. Its structure drawing is shown in Fig.1.

\subsection{Ascertain the weight of the indices}

The weight coefficients of indicators at all levels are fixed by Analytic Hierarchy Process algorithm (AHP) developed by Saaty. (An Shaoshan et al. 2003). AHP algorithm is a multi-objective decision analytical method that combines qualitative with quantitative analysis and also a kind of optimization techniques. AHP algorithm combines qualitative analysis with quantitative analysis organically during programmed decision-making, so it can be used to calculate the weight of each indicator(Cai Kangying et al., 2008; Chen Ruyun et al., 2007)

\section{1) Construct comparison judgment matrix:}

By pairwise comparing elements of the same layer in accordance with certain upper factor, each element of the judgment matrix is able to be defined.The relative importance of each element followes 1-9 proportion evaluation scale. Several judgment matrixes can be eatablished based on the scores that experts provided.The judgment matrixes of rural informatization assessement are shown in Table1-6.

Table 1. A- $\mathrm{C}_{\mathrm{i}}$ Comparison judgment matrix

\begin{tabular}{cccccc}
\hline$A$ & $C_{1}$ & $C_{2}$ & $C_{3}$ & $C_{4}$ & $C_{5}$ \\
\hline$C_{1}$ & 1.000 & 0.7639 & 1.0234 & 0.6806 & 0.7556 \\
$C_{2}$ & 1.4263 & 1.000 & 1.6226 & 0.9250 & 1.0694 \\
$C_{3}$ & 1.1592 & 0.9528 & 1.000 & 0.8222 & 0.8250 \\
$C_{4}$ & 1.5929 & 1.1194 & 1.7782 & 1.000 & 1.0167 \\
$C_{5}$ & 1.4925 & 1.1639 & 1.5048 & 1.0333 & 1.000 \\
\hline
\end{tabular}


Table 2. $\mathrm{C}_{1}-\mathrm{P}$ Comparison judgment matrix

\begin{tabular}{ccccc}
\hline C1 & P1 & P2 & P3 & P4 \\
\hline P1 & 1.000 & 1.819 & 1.522 & 1.825 \\
P2 & 0.625 & 1.000 & 0.995 & 1.119 \\
P3 & 0.739 & 1.414 & 1.000 & 1.2361 \\
P4 & 0.626 & 1.097 & 0.862 & 1.000 \\
\hline
\end{tabular}

Table 3. $\mathrm{C}_{2}$-P Comparison judgment matrix

\begin{tabular}{ccccc}
\hline C2 & P5 & P6 & P7 & P8 \\
\hline P5 & 1.000 & 0.944 & 0.814 & 0.962 \\
P6 & 1.083 & 1.000 & 0.869 & 1.045 \\
P7 & 1.264 & 1.181 & 1.000 & 1.191 \\
P8 & 1.139 & 1.083 & 0.907 & 1.000 \\
\hline
\end{tabular}

Table 4. $\mathrm{C}_{3}$-P Comparison judgment matrix

\begin{tabular}{ccccc}
\hline C3 & P9 & P10 & P11 & P12 \\
\hline P9 & 1.000 & 1.097 & 1.200 & 1.053 \\
P10 & 1.002 & 1.000 & 1.193 & 1.058 \\
P11 & 0.867 & 0.953 & 1.000 & 0.851 \\
P12 & 1.093 & 1.213 & 1.233 & 1.000 \\
\hline
\end{tabular}

Table 5. $\mathrm{C}_{4}$-P Comparison judgment matrix

\begin{tabular}{ccccc}
\hline C4 & P13 & P14 & P15 & P16 \\
\hline P13 & 1.000 & 1.197 & 1.170 & 1.035 \\
P14 & 0.910 & 1.000 & 1.014 & 1.008 \\
P15 & 0.881 & 1.083 & 1.000 & 0.957 \\
P16 & 0.970 & 1.137 & 1.013 & 1.000 \\
\hline
\end{tabular}

Table 6. $\mathrm{C}_{5}-\mathrm{P}$ Comparison judgment matrix

\begin{tabular}{ccccc}
\hline C5 & P17 & P18 & P19 & P20 \\
\hline P17 & 1.000 & 1.138 & 1.268 & 0.885 \\
P18 & 0.940 & 1.000 & 1.155 & 0.822 \\
P19 & 0.810 & 0.890 & 1.000 & 0.696 \\
P20 & 1.217 & 1.352 & 1.486 & 1.000 \\
\hline
\end{tabular}

\section{2) Monolayer weights order}

The importance that each element of No. $(\mathrm{k}+1)$ layer relative to No.k layer is orderd according to the judgment matrix. The order is expressed by the relative value such as follows:

$$
W_{C}=\left[\begin{array}{l}
W_{C_{1}} \\
W_{C_{2}} \\
W_{C_{3}} \\
W_{C_{4}} \\
W_{C_{5}}
\end{array}\right] \quad \sum_{i=1}^{5} W_{C_{i}}=1
$$


Where: $W_{C i}$ is the importance value of the $i$ th $C$ layer relative to $A$ layer.

$W_{C_{i}}$ is calculated by adopting geometric average algorithm. The steps are as follows:

a) Calculate the product of elements of each row:

$$
M_{C_{i}}=\prod_{j=1}^{5} C_{i j} \quad(i=1,2,3,4,5)
$$

b) Calculate the 5 th root of $M_{C_{i}}$ :

$$
\bar{W}_{c_{i}}=\sqrt[5]{M_{C_{i}}}
$$

c) Do standardization with $\bar{W}_{C_{i}}$ :

$$
W_{C_{i}}=\frac{\bar{W}_{C_{i}}}{\sum_{i=1}^{5} \bar{W}_{C_{i}}}
$$

\section{3) Consistency test}

To ensure the monolayer weights order are correct, the judgment matrix should be dealed with consistency test. They are judged by the random consistency ratio $\mathrm{CR}$. If $\mathrm{CR}<0.1$, the results can meet the requirements. Consistency should be tested as follows:

a) Computing consistency index $C I$ :

$$
C I=\left(\lambda_{\max }-n\right) /(n-1)
$$

Where: $\lambda_{\max }$ is the eigenvalue of maximum, $n$ is the number of the order of judgment matrix.

b) Checking the value of the average random consistency index $R I$ from Table7.

Table 7. Values of $R I$

\begin{tabular}{ccccccccc}
\hline$n$ & 1 & 2 & 3 & 4 & 5 & 6 & 7 & 8 \\
\hline $\mathrm{RI}$ & 0.00 & 0.00 & 0.58 & 0.89 & 1.12 & 1.24 & 1.36 & 1.41 \\
$\mathrm{n}$ & 9 & 10 & 11 & 12 & 13 & 14 & 15 & \\
$\mathrm{RI}$ & 1.46 & 1.49 & 1.52 & 1.54 & 1.56 & 1.58 & 1.59 & \\
\hline
\end{tabular}

a) Calculating consistency ratio $C R$ :

$$
C R=C I / R I
$$


If $C R<0.1$, the consistency of the judgment matrix can be satisfied and so the order weights accepted.

By means mentioned above, all of the monolayer weights order can be get: $W_{1}=[0.344,0.210,0.245,0.201], W_{2}=[0.226,0.243,0.281,0.251], W_{3}=$ $[0.259,0.253,0.218,0.270] ; W_{4}=[0.269,0.241,0.239,0.252] ; W_{5}=[0.262$, $0.239,0.207,0.308] ; W=[0.153,0.217,0.174,0.232,0.224]$,

The values of $\lambda_{\max }$ of the the judgment matrix are: 4.262, 4.094, 4.184, 4.084, 4.082, 5.389.

The values of $\mathrm{CR}$ are:0.098, 0.036, 0.069, 0.031, 0.031,0.087. they are all less than 0.1 , so can pass the consistency test.

\subsection{Value of Comprehensive assessment}

Based on the assessment factor matrix $\mathrm{X}$ and the monolayer weights matrix $W_{C i}$, the value of comprehensive assessment of rural informatization level can be determined, the formula is described as follows:

$$
\mathrm{V}=\sum_{i=1}^{5} \overline{X_{i}} W_{C i} \quad(i=1,2,3,4,5)
$$

Where: $\mathrm{V}$ is the level of comprehensive assessment on rural informatization development, $\overline{X_{i}}$ is the assessment factor matrix that made by standard operation.

\section{CONCLUSION}

From five main contents of rural informatization which are: development environment, information infrastructure, information resource, information service system and application of information technology in rural areas, This paper establishes an indicator system for rural informatization assessment and make a study of evaluation method furthermore. By use of AHP algorithm, the paper constructs the hierarchical structure model of rural informatization assessment and calculates the weight of each factor. The comprehensive assessment model we design has preferable operability and practicability. It combines subjective evaluation with objective appraisal, qualitative with quantitative study, and fully considers each assessment factor. Therefore, it is scientific and reasonable and suit to be used to evaluate the level of rural informatization development. 


\section{ACKNOWLEDGEMENTS}

This study is part of the work of the Project:Index system for rural informatization assessment of JiangSu province and supported by JiangSu Information Industry Department.

\section{REFERENCES}

An Shaoshan, Chang Qingrui. Study on the characteristic properties and genesis of land desertication cation in the agriculture and husbandry interlace zone, ACTA Ecologica Sinica, 23(2003): 106-111.

Cai Kangying, Ding Zhuo, Zhou Yannian. Research on evaluation method for government functions based on AHP model, Computer Engineering and Design, 2008,29(7):1834-1837

Chen Ruyun, Fu Baolong. Application of AHP in college library information management level evaluation, Science Technology and Engineering, 2007,7(17):4425-4428

Liu Shihong. Study on the indicator system for measuring the rural area informatization level in China, Library And Information Service, 2007,51(9):33-35

$\mathrm{Lu}$ Lina. Construction of index system for IT application in agriculture, Journal of Library and Information Sciences in Agriculture, 2007,19(4):178-183

Qin Xiangyang, Zhang Xicai, Zhang Xingxiao. Study on assessment index system for rural informatization in Beijing, Journal of Beijing Agricultural Vocation College, 2008,22(1):42-46

Sheng Qifeng. Study on agricultural informazation construction and assessment. Master degree dissertation, Anhui Agricultural University, 2005

Tan Guoliang, He Wei. A study on contents, obstacles and countermeasures of rural informatization in China, Journal of Jiangxi Agricultural University, 2007,6(2):86-88

Yi YaXin. Assessment about the agricultural informatization development in Guangzhou, Master degree dissertation, South China Agricultural University, 2004

Zang Chunrong, Chen Xiao, Liu Shanwen, et al. Present situation analysis of China rural informatization development, Journal of Hunan Agricultural University(Social Sciences), 2004,4(5):10-13(in Chinese) 